\title{
Effect of Genotype, Explant and Hormonal Concentration on in Vitro Response of Eggplant
}

\author{
Dhavala. V. N. CHAKRAVARTHI' ${ }^{1)}$, Vijaya INDUKURI ${ }^{1)}$,Uttam \\ A. GOPARAJU'), Venkateswrarao YECHURI ${ }^{2)}$ \\ ${ }^{1)}$ MAS Lab, DSR - ICAR, Rajendranagar, Hyderabad, India; vncdhavala@gmail.com \\ 2)Andhra University, Department of Botany,Visakhapatnam, India; raovyechuri@yahoo.co.in
}

\begin{abstract}
Three wild relatives Solanum: S. trilobatum L. (P1), S. indicum L. (P2), S. surattense Burm F. (P3) and four cultivars of S. melongena L.: 'Pusa Kranthi' (P4), 'Pusa purple long' (P5), 'Pusa purple cluster' (P6) and 'Green round' (P7) were evaluated for their callus induction frequency, total callus quantity, embryogenic callus quantity and plant regeneration ability. The present experiment revealed that in vitro response was significantly affected by the genotype, hormonal concentration and age of the explants $(\mathrm{P}<0.05)$. Cotyledon at walking stick stage of explants responded more than the opened leaves stage in all genotypes except in P1. Out of seven genotypes, P3 exhibited the highest callus induction, E-callus and regeneration response followed by P5 while highest total callus quantity obtained in P4. MS medium supplemented with $2 \mathrm{mg} / \mathrm{l} \mathrm{NAA}+2.5 \mathrm{mg} / \mathrm{l} \mathrm{BAP}$ was optimum for callus initiation, total callus quantity and embryogenic callus formation, and MS medium supplemented with $2.5 \mathrm{mg} / \mathrm{l}$ each BAP and KN were optimum for regeneration. Rooting of shoots occurred on half strength MS medium supplemented with 1 and $1.5 \mathrm{mg} / \mathrm{l}$ IBA respectively. The rooted plant lets were well accomplished with a survival frequency of $85.5 \pm 5 \%$. Moreover, there were no phenotypic differences observed between the in vitro regenerated and in vivo plantlets.
\end{abstract}

Keywords: genotype, developmental window, Solanum, S. trilobatum, S. indicum, S. surattense, S. melongena

\section{Introduction}

The genus Solanum is predominant to Central and South America and some of the species have originated in Indian subcontinent, including the cultivated eggplant (Solanum melongena). There are over 1400 species in the genus Solanum, which include trees, shrubs, biennials, perennials and climbers (Botanica), which have been broadly recognized as tuberiferous and non-tuberiferous (Hawkes, 1944) and a majority of later category are non-spinous. The genus Solanum is a medicinally important member of the family Solanaceae, well known for the presence of steroidal alkaloids, mainly Solasonine and Solamargine. It is also a good system for transformation studies since plant regeneration via direct and indirect regeneration can be easily achieved in different species and cultivars of the Solanum (Collonnier et al., 2001; Kashyap et al., 2003; Kantharajah and Golegaonkar, 2004; Magioli and Mansur, 2005).

Gene transfer in Solanum through direct or indirect somatic hybridization is not only depending on the efficient in vitro protocol, but also on factors that control in vitro response. In vitro plant regeneration depends on many factors, of which genotype is most important one. Although the genotypic variations have been observed earlier in this species with regard to the both direct and indirect organogenesis (Matsuoka and Hinata, 1979), no systematic study has been under taken to understand the possible reasons for the variations. However, Rao (1992) Sharma and Rajam (1995) demonstrated the effect of genotype, explants and its position on organogenesis and somatic embryogenesis in eggplant, it has confined to only a few cultivars of $S$. molongena $\mathrm{L}$.

Hence the present work was planned to examine the effect of genotype, explant type and hormonal concentrations on four in vitro traits of four cultivars of $S$. melongena and three closely related species of egg plant. An attempt has also been made to catch up the specific developmental window to produce the highest number of multiple shoots from all seven genotypes using two different developmental stages of cotyledonary leaf explants.

\section{Materials and methods}

\section{Plant Materials}

Plant materials used in the present study included three wild species viz., S. trilobatum L., S. indicum L., S. surattense Brum F., and four cultivars of eggplant of $S$. melongena: 'Pusa Kranthi,', 'Pusa purple long', 'Pusa purple cluster' and 'Green round'. These seven are hereafter referred to as accessions and designated as P1, P2, P3, P4, P5, P6 and P7 respectively. Seeds of the wild species were obtained from the National Bureau of Plant Genetic Resources (NBPGR), Pusa Campus, New Delhi, whereas seeds of the four cultivars of $S$. melongena were obtained from Nation- 
78

al Seed Corporation (NSC), Beej Bhavan, Pusa campus, New Delhi, India. All plant materials have been nurtured in the Experimental Farm of Botany Department, Andhra University, Visakhapatnam (India) and have been maintained through self-pollination for two generations.

\section{Developmental stage of the explant}

Seeds obtained from plants of the seven accessions were surface sterilized with $0.01 \%$ Mercuric chloride $\left(\mathrm{HgCl}_{2}\right)$ solution and were sown in sterile soil kept in small plastic cups at room temperature. The seeds were germinated in 4-10 days depending on the genotype. For initial in vitro studies, the explants were collected at three different stages of development of the germinating seedlings.

\section{Stage of explants}

During germination the hypocotyls become erect and lift the seed out of the soil and the two cotyledons are still partially enclosed within the seed coats; seedling at this stage assumes the shape of a walking stick, the cotyledons collected at this stage are designated as Type-I explants. The seed coat bursts open and gets detached from the seedling while the cotyledons get separated from each other and are positioned at $180^{\circ}$ to each other, resulting in the ' $T$ ' shaped seedling; cotyledons collected at this stage are designated as Type II explants (Fig. 1.1). Matured leaves of plantlet at 5 leaves stage are designated as Type III explants (Fig. 1.2)

The seedlings attained walking stick stage in 5 to 12 days after sowing. Within four or five days after reaching the walking stick stage, the seedlings attain the ' $T$ ' stage and these plantlets reaching the 5 leaves stage in 4 to 5 weeks after sowing were screened for initial in vitro response in all genotypes. While comparing the initial response of these three explants the cotyledonary leaves at two stages of development were responded better than matured leaves in all the accessions (data not shown). Hence cotyledonary leaves at these two stages were used to catch up the developmental window to get the highest in vitro response at different combinational concentrations of different hormones.

\section{Culture medium}

MS (Murashige and Skoog, 1962) medium containing $30 \mathrm{~g} / \mathrm{l}$ sucrose supplemented with various concentrations of 2,4-D, IAA, NAA, 6-Benzyl amino purine (BAP), Kinetin $(\mathrm{KN})$ (Himedia and Qualigens India LTD, Sigma chemical co., U.S.A.) either alone or in combinations have been used for in vitro studies. The medium was adjusted to a $\mathrm{pH}$ of 5.8 prior to autoclaving and solidified with 0.8 percent (w/v) agar (Bacteriological grade, Qualigens Chemical Co.). MS basal medium without any hormones served as the control in all these experiments.

\section{Culture conditions}

The sterilization of media and glassware was carried out in an autoclave at $120^{\circ} \mathrm{C}$ and $15 \mathrm{lb} /$ in $^{2}$ pressure for $15 \mathrm{~min}$ utes. The type I and II explants were washed under running tap water followed by three washes in distilled water. Then they were treated with $0.01 \%$ Mercuric chloride $\left(\mathrm{Hgcl}_{2}\right)$ for five minutes and washed thrice in sterile distilled water in order to wash out traces of the sterilent. Extreme basal and terminal regions of cotyledons were discarded and the middle portions were cut into two equal segments and then inoculated on MS medium supplemented with different hormones separately and also in combinations. All these operations were carried out under a Laminar Air Flow unit (Klenzaids, Model 1103, with Gradvel filter). Transfer of cultures to fresh media (sub culturing) was carried out at the end of every third week. All cultures were maintained at $26 \pm 2^{\circ} \mathrm{C}$. For regeneration, the cultures were maintained under an intensity of 3000 lux of cool white fluorescent light for $16 \mathrm{~h} /$ day.

\section{Experimental design}

Cotyledons at two stages of seedlings were harvested and each was cut into two equal segments and inoculated into MS medium supplemented with $2 \mathrm{mg} / \mathrm{l} \mathrm{NAA}$ and different concentrations of BAP (MSNB). Explants were sub cultured for every end of second week to avoid nutrient stress. At the end of second subculture callus segments transferred to same MSNB media for measuring callus quantities, while for shoot formation and elongation, callus segments were transferred to MSKB media consisting of equal concentrations of $\mathrm{KN}$ and BAP from $0.5 \mathrm{mg} / \mathrm{l}$ to 3.5 $\mathrm{mg} / \mathrm{l}$. In order to observe optimum regeneration response, two types of explants were cultured on different concentration of BAP (MSB) in separate experiment. A total of 10-15 segments were used in each treatment, which was replicated for four times. A minimum of 40 cotyledonary segments from each accessions were cultured and data on following traits were collected as follows.

The percentage of explants producing callus was counted and expressed as the frequency of callus induction, while the volume of embryogenic (E) and non-embryogenic (NE) type together were considered as the total callus quantity. Callus volume was measured, six weeks after inoculation. For measuring volumes of total callus and embryogenic callus, a thin transparent polythene graph paper drawn in millimeters was used and to measure the height of the callus a small transparent plastic scale drawn in millimeters was used. Area of the callus and its height were measured by counting the number of squares covering the callus. For example, if the callus occupied 0.25 $\mathrm{cm}^{2}$ area on the graph paper and if its height was $0.5 \mathrm{~cm}$, then the volume occupied by the callus was calculated as $0.25 \times 0.5$ i.e., $0.125 \mathrm{~cm}^{3}$. Embryogenic callus volume was expressed in terms of percentage proportion in total callus volume (volume of E- callus / Total callus volume x 100). The number of shoots produced by the explants inocu- 
lated was counted and is expressed in terms of the average number of shoots per explant. The shoots harvested from the media were transferred into half strength MS medium supplemented with different concentrations of IBA from $0-5 \mathrm{mg} / \mathrm{l}$ with $0.5 \mathrm{mg} / \mathrm{l}$ interval for rooting.

\section{Statistical analysis}

The effects of genotypes and hormone treatments were tested by using two-way ANOVA and to find out the effect of two types of explants among all concentrations as well as all genotypes on various in vitro characters one-way ANOVA has been carried out. Correlation coefficients were calculated to study the effect of NAA, BAP and KN alone and in combinations on various characters of the callus Viz., callus initiation frequency, callus quantities $(\mathrm{E}+\mathrm{NE})$ and average number of shoots. Computation of ANOVA and correlation coefficients were carried out following Snedecor (1961).

\section{Results}

\section{Callus initiation frequency}

The explants cultured initially on 24-D or IAA did not reveal any in vitro response in any of the ten concentrations $(0.5$ to $5 \mathrm{mg} / \mathrm{l})$. Explants inoculated on 0.5 to $2 \mathrm{mg} / \mathrm{l}$ concentration of NAA produced roots while those cultured on $2.5 \mathrm{mg} / \mathrm{l}$ to $5 \mathrm{mg} / \mathrm{l}$ concentration of NAA produced rooty callus. These calli even when transferred on to regeneration medium containing BAP and $\mathrm{KN}$ did not show regeneration (Fig. 1.10).

However, two types of explants cultured on various combinational concentrations of NAA and BAP ( 0.5 to $3.5 \mathrm{mg} / \mathrm{l}$ each) produced callus from the cut ends more so at the morphologically upper end than lower end, the highest frequency obtained only at $2 \mathrm{mg} / \mathrm{l} \mathrm{NAA}+2.5$ $\mathrm{mg} / \mathrm{l}$ BAP concentration in all genotypes except $\mathrm{P} 1$ where $2 \mathrm{mg} / \mathrm{lNAA}+3 \mathrm{mg} / \mathrm{l}$ of BAP concentration was found to be optimum. Callus initiation frequency increased gradually with the increasing concentrations of NAA and BAP from 0.5 to 2 and $2.5 \mathrm{mg} / \mathrm{l}$ respectively (Fig. 2A). Since $2 \mathrm{mg} / \mathrm{l}$ of NAA concentration found to be optimum, different concentrations of BAP in combination with $2 \mathrm{mg} / \mathrm{l}$ NAA has been used to observe the effect of genotype, explant type and different hormonal concentrations on in vitro response. Response of the callus induction frequency varied from 12 to $90 \%$. The highest percent of callus induction was obtained from the Type I explant of P3. Of the two types of explants used, Type 1 explants responded better than Type II in all concentrations as well as in all seven genotypes except in P1.

To assess the difference obtained in the callus initiation frequencies from type - 1 explant of seven accessions and in seven different concentrations of BAP $+2 \mathrm{mg} / \mathrm{l} \mathrm{NAA}$, the data was subjected to a two way ANOVA which revealed the existence of significant differences among the seven genotypes and also between the concentrations. Similar results were obtained in the case of explant II derived calluses also. Significant difference between two explants for callus induction frequency among all concentrations as well as all genotypes was observed by one way ANOVA $(\mathrm{p}>0.05$, Tab. 1).

\section{Callus quantity}

Data on callus volume was recorded at $6^{\text {th }}$ week after the inoculation from the two types of explants. Five (P2, P3, P4, P6 and P7) out of the seven accessions showed an increase in the total callus volume $\left(\mathrm{cm}^{3}\right)$ from 0.5 to 2.5 $\mathrm{mg} / \mathrm{l} \mathrm{BAP}$ and a decrease in 3 and $3.5 \mathrm{mg} / \mathrm{l}$ in the remaining two accessions (P1 and $\mathrm{P} 5$ ) maximum callus quantity was observed in $3 \mathrm{mg} / \mathrm{l}$. thus, in general, $2.0 \mathrm{mg} / \mathrm{l}$ of NAA

Tab. 1. Estimation of variance on genotype, hormonal concentration and explant type in four in vitro characters

\begin{tabular}{|c|c|c|c|c|c|c|c|c|c|c|}
\hline \multirow{3}{*}{ Source $^{\mathrm{a}}$} & \multicolumn{6}{|c|}{$2 \mathrm{mg} / \mathrm{lNAA}+$ different concentration of BAP } & \multirow{2}{*}{\multicolumn{2}{|c|}{$\begin{array}{c}\text { KN+BAP } \\
\text { Avg. number } \\
\text { of shoots }\end{array}$}} & \multirow{2}{*}{\multicolumn{2}{|c|}{$\begin{array}{c}\text { BAP alone } \\
\text { Avg. number } \\
\text { of shoots }\end{array}$}} \\
\hline & \multicolumn{2}{|c|}{ Callus initiation } & \multicolumn{2}{|c|}{ Callus quantity } & \multicolumn{2}{|c|}{ E-callus quantity } & & & & \\
\hline & $\mathrm{df}$ & MS & $\mathrm{df}$ & MS & $\mathrm{df}$ & MS & $\mathrm{df}$ & MS & $\mathrm{df}$ & MS \\
\hline \multicolumn{11}{|c|}{ Type-I explant } \\
\hline Genotype & 6 & $308.33^{* *}$ & 6 & $1.113^{* *}$ & 6 & $2159.53^{* *}$ & 6 & $7036.05^{* *}$ & 6 & $8031.92^{* *}$ \\
\hline BAPconc. & 6 & $3669.26^{* *}$ & 6 & $5.626^{* *}$ & 6 & $1230.23^{* *}$ & 6 & $1245.38^{* *}$ & 6 & $1474.29^{* *}$ \\
\hline Error & 36 & 83.04 & 36 & 0.135 & 36 & 63.58 & 36 & 519.00 & 36 & 367.38 \\
\hline \multicolumn{11}{|c|}{ Type-II explant } \\
\hline Genotype & 6 & $693.69^{* *}$ & 6 & $0.65^{* *}$ & 6 & $3150.29^{* *}$ & 6 & $4686.71^{* *}$ & 6 & $5216.08^{* *}$ \\
\hline BAPconc. & 6 & $2520.35^{* *}$ & 6 & $3.68^{* *}$ & 6 & $786.23^{* *}$ & 6 & $715.92^{* *}$ & 6 & $888.73^{* *}$ \\
\hline Error & 36 & 95.04 & 36 & 0.075 & 36 & 57.55 & 36 & 233.39 & 36 & 216.25 \\
\hline \multicolumn{11}{|c|}{ Between explants } \\
\hline Explant type & 1 & $1926.43^{* *}$ & 1 & $1.85^{* *}$ & 1 & $457.01^{* *}$ & 1 & $201.35^{*}$ & 1 & $587.76^{* *}$ \\
\hline Error & 48 & 58.40 & 48 & 0.037 & 48 & 49.30 & 48 & 55.20 & 48 & 39.37 \\
\hline
\end{tabular}

${ }^{*} \mathrm{P}<0.05,{ }^{*}$ indicates the percentage of contribution is equal to 0.06 . 
80

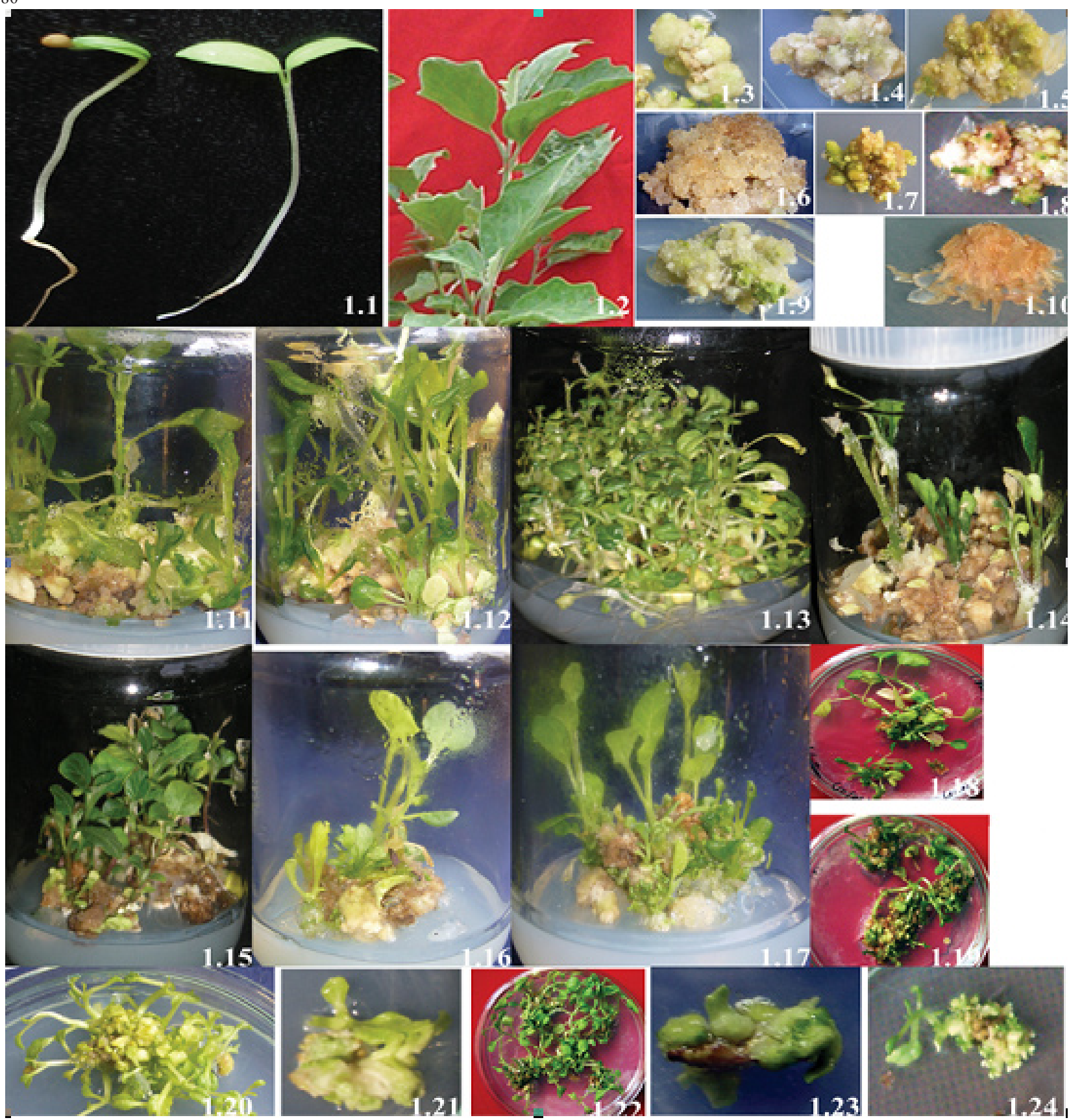

Fig. 1. In vitro response of type-I explants of Solanum genotypes: (1.1-1.2) explant types; (1.3-1.9) Callus segments of different genotypes showing variation in the morphology and quantities of embryogenic and non embryogenic portions; (1.10) Rooty callus; (1.11-1.17) Differential response of seven genotypes on multiple shoots in MSKB medium; (1.18-1.24) Response of seven genotypes on direct regeneration in BAP supplemented medium. All the calluses and multiple shoots shown were nearly at the same development stage and in the same culture condition.

$+2.5 \mathrm{mg} / \mathrm{l} \mathrm{BAP}$ was observed to be the optimum concentration inducing larger quantities of callus from the two types of explants.

A comparison of the callus quantities produced by both the explants revealed that the quantities of total calli are relatively lower in type-II explants than in type-I explants in majority of the concentrations and in all accessions the deviations from this trend were noticed in 0.5 $\mathrm{mg} / \mathrm{l}, 2.5 \mathrm{mg} / \mathrm{l}$ and $3 \mathrm{mg} / \mathrm{l}$ of $\mathrm{P} 1$ and $3.5 \mathrm{mg} / \mathrm{l}$ of P3 and PG where type-II explants produced slightly more quantities of calli than type-I (Fig. 2B). In general, when the performance of the seven accessions with regard to quantity of total callus was considered, P4 was found to be the best one which produced larger quantities $\left(3.95\right.$ and $3.3 \mathrm{~cm}^{3}$ respectively) from both the explant sources and in nearly all hormonal treatments (Fig. 1.3-1.9). ANOVA revealed highly significant differences between the seven accessions and also between concentrations of NAA + BAP and two 
A

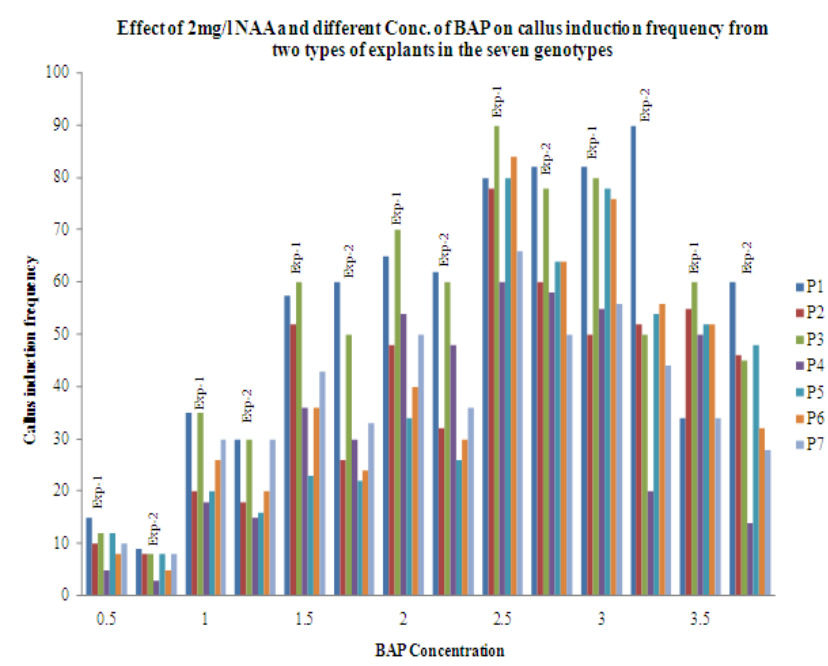

C

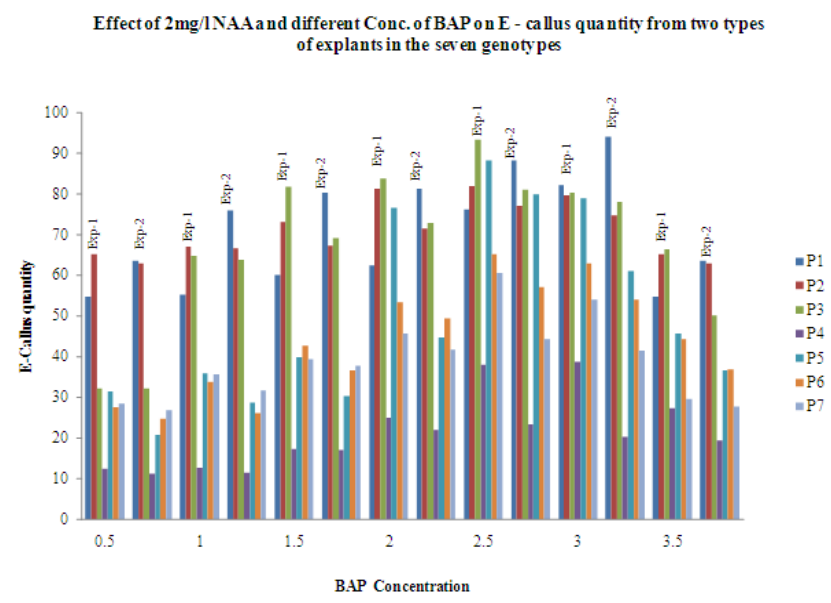

B

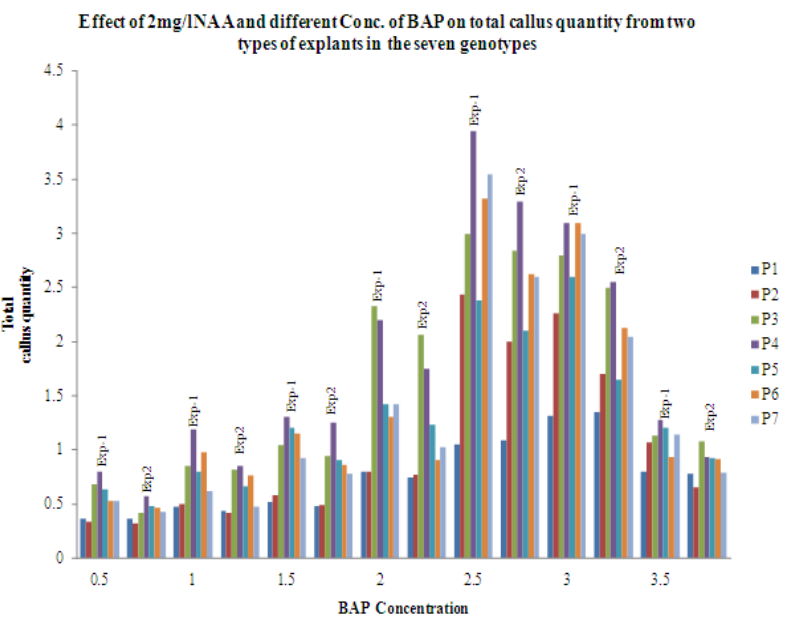

D

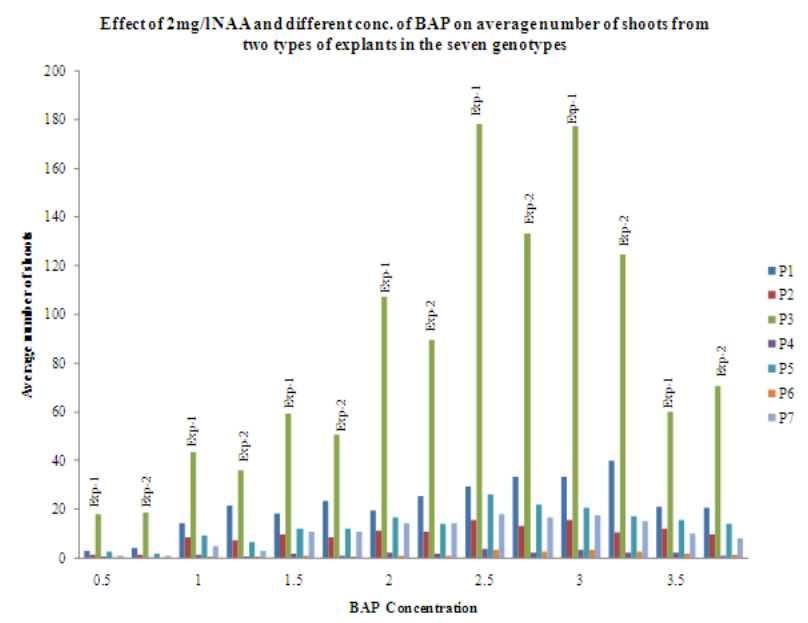

E

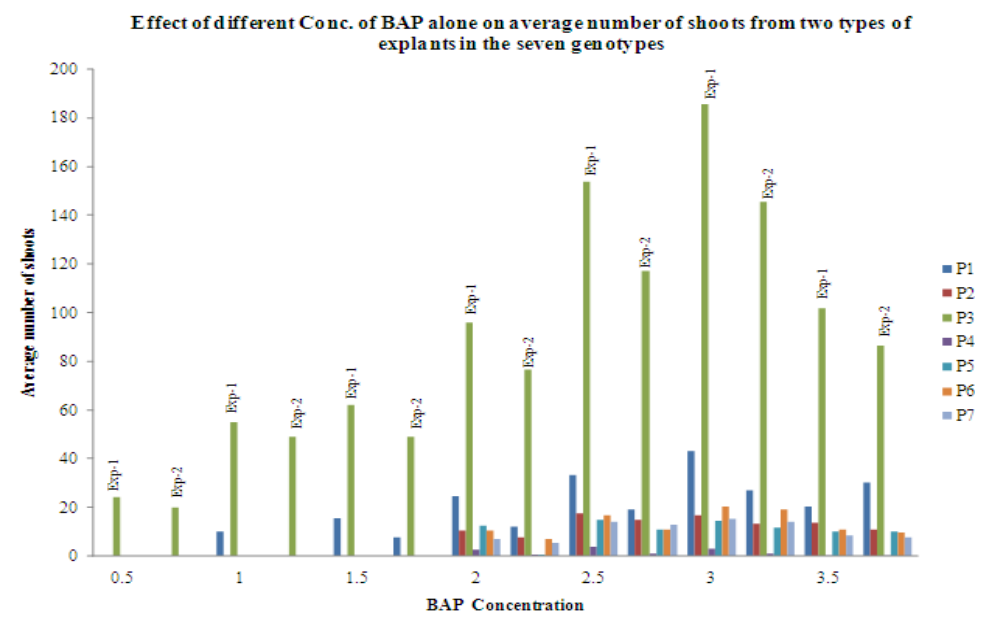

Fig. 2. Graphs for In vitro response of two types of explants of seven Solanum genotypes: A) callus initiation; B) callus quantity; C) E-callus quantity; D) Avg. Number of shoots in MSKB; E) Avg. Number of shoots in BAP 
82

types of explants used $(\mathrm{P}<0.05$, Tab. 1$)$. When data on total callus volume as a function of increasing concentration of BAP (in association with $2.0 \mathrm{mg} / \mathrm{l} \mathrm{NAA}$ ) was subjected to correlation, significant positive correlation was observed only in two cases i.e., P1 of explant type -1 and P3 of explant type II $(p<0.05)$. In other cases the correlation coefficients were positive but were not significant $(\mathrm{p}$ $>0.05)$.

\section{Embryogenic callus quantity}

E-callus quantity also followed the same trend as that of callus quantity, in all the accessions quantity of E-callus increased from 0.5 to $2.5 \mathrm{mg} / \mathrm{l}$ and it was decreased in the higher concentrations used in both the explant types, except in P1. Maximum quantity of embryogenic callus was recorded in $3 \mathrm{mg} / \mathrm{l} \mathrm{BAP}$ in type II explants (94.07) of P1 followed by $2.5 \mathrm{mg} / \mathrm{l}$ in P3 of type I explant (93.33). P4 accession produced minimum quantities of E-callus from both explant types irrespective of the concentrations of BAP used (Fig. 2C). Highly significant genotypic and treatment and explant differences was observed by ANOVA $(\mathrm{p}<0.05$, Tab. 1$)$

\section{Average number of shoots}

Callus induced on $2.5 \mathrm{mg} / \mathrm{l} \mathrm{NAA}+$ various concentrations of BAP ( 0.5 to $3.5 \mathrm{mg} / \mathrm{l})$ started producing shoots when subcultured onto MS medium supplemented with each 0.5 to $3.5 \mathrm{mg} / \mathrm{l} \mathrm{BAP}$ and $\mathrm{KN}$. The number shoots were separated and counted at the end of $8^{\text {th }}$ week after inoculation. The present study revealed the increase in the number of shoots with an increase in the concentration of $\mathrm{KN}$ and BAP from 0.5 to $2.5 \mathrm{mg} / \mathrm{l}$ in all the accessions except P1 and P6 where the maximum was observed in 3 $\mathrm{mg} / \mathrm{l} \mathrm{KN}$. Among the seven accessions maximum shoot number (178.2) was recorded in P3 and the minimum was noticed in P6 (Fig. 1.11-1.17). Significant differences between accessions as well as between concentration $(p<0.05)$ were indicated by the two way ANOVA. Differences obtained from two types of explants were positive but not significant at 0.05 . The data on correlation analysis revealed a significant increase in average shoot number with increase in the concentrations of $\mathrm{KN}+\mathrm{BN}$ in $\mathrm{P} 1, \mathrm{P} 2$ P5 and P6 in type I explant and in P5 only in type II explants. Of the two types of explants used type -1 explants responded better and produced more number of multiple shoots than type II in all the concentrations as well as in all the seven genotypes (Fig. 2D).

\section{Effect of BAP}

When MS medium supplemented with BAP alone in concentrations ranging from 0.5 to 3.5 , no callus formation was observed irrespective types of explant and the accessions. However direct somatic embryogenesis resulting in gradual development of plant lets was observed in all accessions from $2 \mathrm{mg} / \mathrm{l}$ to $3.5 \mathrm{mg} / \mathrm{l}$ BAP concentrations except in two accessions (P1 and $\mathrm{P} 3$ ) where regeneration was observed from BAP concentrations less than $2 \mathrm{mg} / \mathrm{l}$, in P1 shoots were initiated from 1 and $1.5 \mathrm{mg} / \mathrm{l}$ while in P3 even $0.5 \mathrm{mg} / \mathrm{l}$ BAP produced shoots (Fig. 1.18-1.24). The number of shoots per explants in all genotypes increased with an increase in the BAP concentration up to $3 \mathrm{mg} / \mathrm{l}$. Among all the accessions, $\mathrm{P} 3$ produced highest frequency (185) in all BAP concentration followed by P1, while P4 produced the minimum number (Fig. 2e). Highly significant variations observed among the genotype, concentration of BAP and explant type by two way and one way ANOVAs respectively.

\section{Rooting and hardening}

Well developed shoots ( $5 \mathrm{~cm}$ height) were transferred onto rooting medium containing different concentrations $(0-5 \mathrm{mg} / \mathrm{l}$ with $0.5 \mathrm{mg} / \mathrm{l}$ interval) of IBA, the best rooting response observed on half strength MS medium fortified with $1.5 \mathrm{mg} / \mathrm{l}(87 \% \pm 8)$ followed by $1 \mathrm{mg} / \mathrm{l}(72 \% \pm 6)$ in both types of explant sources in all the genotypes. Plant lets at five leaves stage were transferred to sterilized soil + vermiculate mix (1:1) in growth chamber for two weeks and further they were transferred into the pots and experimental garden. Plants regenerated from two types of explants were phenotypically normal and uniform in their growth in the green house and did not reveal any variation.

\section{Discussion}

It is now well established fact that in a number of plant systems, several intrinsic and extrinsic factors influence tissue culture response. Among these factors, the nature and age of the explant, the genotype, type of phytohormones and their concentrations play a major role. A survey of information from the earlier works on non-tuberiferous solanums revealed the major role played by these factors and also the variations that existed in their effects (Collonnier et al., 2001; Kashyap et al., 2003; Kantharajha and Golegaonkar, 2004). Of these factors the explant age is found to be the critical factor in effecting callus induction and subsequent shoot formation.

In $S$. melongena, regeneration from the cotyledonary explants at different developmental stages ranging from one week old to 30 days old have been reported (Alicchio et al., 1982; Fobert and Webb, 1988; Rao, 1992; Saito and Nishimura, 1994; Momiyama et al., 1995; Sharma and Rajam, 1995; Hitomi et al., 1998; Magioli et al., 1998; Scoccianti et al., 2000; Tarre et al., 2004; Rahaman et al., 2006). Rama Swami et al. (2005) reported in vitro response of cotyledons from three week old seedlings of S. surattense. Of the two stages of cotyledonary explants used in the present study, one week old (type I explants) were highly responsive for callus initiation, the quantities of total and embryogenic calli and average number of shoot production (either through direct or indirect somatic embryogenesis) in six out of the seven genotypes, 
than the two week old explants (type II explants). This favorable response observed in the one week old cotyledon explants, suggests the importance of explant age on in vitro response. Saito and Nishimura (1994) arrived at similar conclusion for in vitro characters. Morrish et al. (1987) suggested that there is a particular stage of development "selective phase" and "competence window" to which production of embryogenic callus is confined. Use of explants in this phase was expected to result in maximum in vitro response. The reduction or total lack of response in the explants of relatively older or advanced stage was suggested to be the result of qualitative and quantitative changes of DNA, status of cell cycle, endogenous hormonal levels and / or the genotype. In light of this concept, in the present study, one week old seedlings of the seven genotypes tested except $S$. trilobatum might represent the 'selective phase' or 'developmental window' for manipulation of differentiation path way in solanums.

Even though explants at the same stage of development have been used in all the seven accessions/genotypes in the present work, the variations in their in vitro response might be attributed to the differential response of the genotypes to the various phytohormones and their concentrations. Such genotypic differences have been reported earlier in S. melongena (Yamada et al., 1967; Matsuoka and Hinata, 1979; Alicchio et al., 1982; Ali et al., 1991; Rao, 1992; Sharma and Rajam, 1995; Afele et al., 1996) and in several other crop plants (Bashkaran and Smith, 1990; Ezura et al., 1993; Ochoa Alejo and Ireta-Moreno, 1990; Pundeva and Simeonova, 1992; Tan et al., 1987).

Earlier, different authors reported the use of a variety of phytohormones which included 2,4-D, IAA, NAA, $\mathrm{KN}, \mathrm{BAP}, 2,4,5-\mathrm{T}$, 2-ip, NOA, TDZ and Zeatin for the in vitro experiments using different species/accessions or cultivars of non-tuberiferous solanums. Of these either NAA or BAP alone or in combination have been most widely used for the in vitro morphogenesis in species of Solanaceae. In addition to these, kinetin or BAP alone and a combination of these two cytokinins have also been used (Collonnier et al., 2001; Kashyap et al., 2003; Kantharajha and Golegaonkar, 2004). In the present study, of the various hormones viz., 2,4-D, IAA, NAA, $\mathrm{KN}$ and BAP) used, IAA as well as 2,4-D did not show any in vitro response, NAA when used alone resulted either in rooting from explant or callus formation along with rhizogenesis. $\mathrm{NAA}$ in combination with $\mathrm{KN}$ resulted in low frequency of regeneration, while use of $\mathrm{KN}$ alone resulted in callus formation but not plant let regenerations. Since concentrations of NAA, above $1.5 \mathrm{mg} / \mathrm{l}$ revealed high response for the callus initiation when used in combination with $\mathrm{BAP}$, and since the effect of BAP on somatic embryogenesis was varied from 0.5 to $2.5 \mathrm{mg} / \mathrm{l}$, combinations of each of the $2 \mathrm{mg} / \mathrm{l} \mathrm{NAA}$ with different concentrations (0.5 - 3.5 $\mathrm{mg} / \mathrm{l}) \mathrm{BAP}$ have been used for studying their effects on the in vitro characters. The present results revealed that combination of $2 \mathrm{mg} / \mathrm{l} \mathrm{NAA}+2.5 \mathrm{mg} / \mathrm{l} \mathrm{BAP}$ produced opti- mum results in terms of callus production, total callus and embryogenic callus quantities while for the regeneration $2.5 \mathrm{mg} / \mathrm{l}$ each of BAP and $\mathrm{KN}$ found to be optimum. Use of BAP alone resulted in direct multiple shoot production without a callus phase (direct embryogenesis). The rooting response was best in half strength MS medium fortified with $1.5 \mathrm{mg} / \mathrm{l}$ IBA. Similar occurrence of maximum and healthy rooting response was reported in this plant system by earlier workers on IBA containing MS/LS medium (Collonnier et al., 2001; Kashyap et al., 2003; Kantharajha and Golegaonkar, 2004).

When the quantum of response of the seven genotypes observed at the optimum concentration $(2 \mathrm{mg} / \mathrm{l} \mathrm{NAA}+$ $2.5 \mathrm{mg} / \mathrm{l} \mathrm{BAP}$ and $2.5 \mathrm{mg} / \mathrm{l}$ each $\mathrm{KN}$ and BAP) for the four in vitro characters was considered, it could be observed that the genotype in which maximum response was observed for any one character, did not result in maximum response in the other character(s). For example, $\mathrm{P} 3$ and $\mathrm{P} 1$ showed maximum callus induction frequency while $\mathrm{P} 4$ showed the minimum but when the total callus quantity is considered, $\mathrm{P} 4$ produced maximum quantity of callus, while P1 produced a very low quantity of callus. Similarly, when the quantities of total and embryogenic calli and average number of shoots were considered, P3 was intermediate in total callus quantity but produced maximum embryogenic callus as well as average shoot number, while $\mathrm{P} 4$, which produced maximum total callus, resulted in minimum embryogenic callus as well as average number of shoots. The present results suggest that the quantity of the embryogenic callus and regeneration potential might be the result of interaction between the hormones and the genotypes used. It may be pertinent here to cite the suggestion of Morrish et al. (1987) that the influence of genotype is only discernible when the developmental stage of the organ used and the culture conditions under which different genotypes were grown are similar. The present study satisfies these requirements, since the culture condition, hormonal concentration and the type as well as age of the explant were the same in all the seven accession/ genotypes. This further supports the influence that the differences observed among the seven accessions for various in vitro characters reflect the true genotypic influences.

In the present study even though P3 (S. surattense) was found to be most responsive genotype in terms of embryogenic callus quantity and average number of shoots per explant, among the $S$. melongena cultivars/genotypes used, P5 (S. melongena var. 'Pusa purple long') was also found to be highly responsive standing next to P3. The same cultivar of $S$. melongena was also found to be highly responsive for in vitro studies by Sharma and Rajam (1995). $S$. surattense which is a wild species showed maximum callus induction frequency, E-callus quantity and regeneration potential, but had lower total callus quantity than some of the cultivars. The other two wild species displayed no such clear trend. Pratta Guillermo et al. (2003) also no- 
84

ticed such differential trends between the wild species and cultivars of Lycopersicon.

During the present study an interesting observation made is that the formation of callus as well as embryo formation could be obtained on the same hormonal concentration but at different time intervals, the former during the initial period (up to 2 weeks) of culture and the later after three weeks. Though the explant biochemical or molecular basis of such differential response as a function of culture time could not be ascertained from the present study, it may be conjectured from the information available from earlier works that endogenous hormonal levels as well as those of polyamines might be changing with culture time and may influence the final response (Fobert and Webb, 1988; Sharma and Rajam, 1995; Momiyamma et al., 1995; Yadav and Rajam, 1997, 1998; Scoccianti et al., 2000). The present accessions and explant types might provide suitable experimental system to undertake detailed analysis of these biochemical factors. Apart from this, the present study is useful for producing highest number of plant lets without any seasonal constraints for crop improvement as well as for genetic engineering experiments.

\section{Acknowledgements}

The author thanks Prof. M. V. Subba Rao, Dept of Botany, Andhra University, Visakhapatnam for providing facilities. Thanks are also due to the UGC-SAP for providing financial facilities for this work.

\section{References}

Afele, J. C., Y. Tabei, T. Yamada, T. Momiyama, F. Takaiwa, T. Kayano, S. Nishimura and T. Nishio (1996). Identification of mRNAs differentially expressed between embryogenic and non-embryogenic cultivars of eggplant during somatic embryogenesis. Jpn. Agric. Res. Quart. 30:175-179.

Alicchio, R., E. Del Grosso and E. Boschieri (1982). Tissue culture and plant regeneration from different explants in six cultivars of Solanum melongena. Experientia 38:449-450.

Ali, M., H. Okubo and K. Fujieda (1991). In vitro multiplication of intra- and interspecific solanum hybrids through somatic embryogenesis and adventitious organogenesis. J. Jpn. Soc. Hortic. Sci. 60(3):601-612.

Bashkaran, S. and R. H. Smith (1990). Regeneration in cereal tissue culture: a review. Crop Science 30:1328-1337.

Collonnier, C., I. Fock, V. Kashyap, G. L. Rotino, M. C. Daunay, Y. Lian, I. K. Mariska, M. V. Rajam, A. Servaes, G. Ducreux and D. Sihachakr (2001). Applications of biotechnology in eggplant. Plant Cell, Tissue and Organ Culture 65:91-107.

Ezura, H., S. Nishimiya and M. Kasumi (1993). Efficient regeneration of plants independent of exogenous growth regulators in bell pepper (Capsicum annuum L.). Plant Cell Reports 12:676-680.

Fobert, P. R. and D. T. Webb (1988). Effects of polyamines, polyamine precursors, and polyamine biosynthetic inhibitors on somatic embryogenesis from eggplant (Solanum melongena ) cotyledons. Canadian Journal Botany 66:17341742.

Hawkes, J. G. (1944). Potato collecting expedition in Mexico and America II. Systematic classification of the collections I. A. B. Bull. pp.142 (cited from Magoon et al., 1962).

Hitomi, A., H. Amagai and H. Ezura (1998). The influence of auxin type on the array of somaclonal variants generated from somatic embryogenesis of eggplant, Solanum melongena L. Plant Breeding 117:379-383.

Kantharajah, A. S. and P. G. Golegaonkar (2004). Somatic embryogenesis in eggplant. Scientia Horticulturae 99:107117.

Kashyap, V., S. V. Kumar, C. Collonnier, F. Fusari, R. Haicour, G. L. Rotino, D. Sihachakr and M. V. Rajam (2003). Biotechnology of eggplant. Scientia Horticulturae 97:1-25.

Magioli. C., A. P. M. Rocha and D. E. De Oliveira (1998). Efficient shoot organogenesis of eggplant (Solanum melonga L.) induced by thidiazuron. Plant Cell Reports 17:661-663.

Magioli,C. and E. Mansur (2005). Eggplant (Solanum melongena L.): tissue culture, genetic tansformation and use as an alternative model plant. Acta Botanica Brasilica 19(1):139-148.

Matsuoka, H. and K. Hinata (1979). NAA-induced organogenesis and embryogenesis in hypocotyl callus of Solanum melongena L. Journal of Experimental Botany 30:363-370.

Momiyama, T., J. C. Afele, T. Saito, T. Kayano, Y. Tabei, K. Takaiwa, K. Takayanagi and S. Nishimura (1995). Differential display identifies developmentally regulated genes during somatic embryogenesis in eggplant (Solanum melongena L.). Biochemical and Biophysical Research Communications 213(2):376-382.

Morrish, F., V. Vasil and I. K. Vasil (1987). Developmental morphogenesis and genetic manipulation in tissue and cell cultures of the gramineae. In: J. G. Scandalios (Ed.) "Advances in Genetics" Molecular Genetics of Development 24:431-482.

Murashige, T. and F. Skoog (1962). A revised medium for rapid grow th and bioassays with tobacco tissue culture. Physiologia Plantarum 15:473-497.

Ochoa-Alejo, N. and L. Ireta-Marono (1990). Cultivar differences in shoot forming capacity of hypocotyl tissues of chilli pepper (Capsicum annuum L). cultured in vitro. Scientia Horticulturae 42:21-28.

Pratta Guillermo, R. Zorzoli and L. A. Picardi (2003). Diallel analysis of production traits among domestic, exotic and mutant germplasms of Lycopersicon. Genetics and Molecular Research 2:206-213.

Pundeva, R. and N. Simeonova (1992). Induction of callus and organogenesis in pepper. Capsicum News Letter 11:24-25.

Rahaman, M., M. Asaduzzaman, N. Nahar and M. A. Bari (2006). Efficient plant regeneration from cotyledon and midrib derived callus in eggplant (Solanum melongena L.) 
Journal of Biological Sciences 14:31-38.

Rama Swami, N., T. Ugandhar, M. Praveen, P. Venkataiah, M. Rambabu, M. Upender and K. Subhash (2005). Somatic embryogenesis and plantlet regeneration from cotyledon and leaf explants of Solanum surattence. Indian Journal of Biotechnology 4:414-418.

Rao, P. V. L. (1992). Difference in somatic embryogenitic ability of cultured leaf explants of four genotypes of Solanum melongena L. Agronomie 12(6):469-475.

Saito, T. and T. Nishimura (1994). Improved culture conditions for somatic embryogenesis using in aseptic ventilative filter in eggplant (Solanum melongena L.). Plant Sciences 102:205-211.

Scoccianti, V., E. Sgarbi, D. Fraternale and S. Biondi (2000). Organogenesis from Solanum melongena L. (egg plant) cotyledon explants is associated with hormone-modulated enhancement of polyamine biosynthesis and conjugation. Protoplasma 211:51-63.

Sharma, P. and M. V. Rajam (1995). Genotype, explant and position effects on organogenesis and somatic embryogenesis in eggplant (Solanum melongena L.). Journal of Experimental Botany 46:135-141.

Snedecor, G. W. (1961). Statistical methods. Iowa state college press, AMES, Iowa USA. Indian edition 1961. Allied pacific private limited, Bombay.
Tan M. M. C., C. M. Colijn-Hooymans, W. H. Lindhout and A. J. Kool (1987). A comparison of shoot regeneration from protoplasts and leaf discs of different genotypes of the cultivated tomato. Theoretical and Applied Genetics 75:105-108.

Tarre, E., C. Mogioli, M. M. Pinheiro, G. S. Martins, D. R. E. Mansur and S. Fernandes (2004). In vitro somatic embryogenesis and adventitious root initiation have a common origin in eggplant (Solanum melongena L.). Revista Brasileira de Botanica 27:79-84.

Yadav, J. S. and M. V. Rajam (1997). Spatial distribution of free and conjugated polyamines in leaves of Solanum melongena L. associated with differential morphogenetic capacity: Efficient somatic embryogenesis with putrescine. Journal of Experimental Botany 48:1537-1545.

Yadav, J. S. and M. V. Rajam (1998). Temporal regulation of somatic embryogenesis by adjusting cellular polyamine content in eggplant. Plant Physiology 116: 617-625.

Yamada, T., H. Nakagawa and Y. Sinoto (1967). Studies on the differentiation in cultured cells. I. Embryogenesis in three strains of Solanum callus. Botanical Magazine Tokyo 80:6874. 